\title{
UNA POÉTICA DE LA HERIDA EN BELGRADO DE ANGÉLICA DE LIDDELL* A POETIC OF WOUND IN ANGÉLICA LIDDELL'S BELGRADO
}

\author{
PATRicia Úbeda SÁNChEZ \\ Universidad de Almería
}

\begin{abstract}
RESUMEN
En este estudio analizaremos dos núcleos semióticos con los que Angélica Liddell va a basar la estructura interna de su obra, Belgrado: la herida y la cicatriz. Con estos dos motivos epidérmicos comprobaremos que la escritura liddelliana está atravesada por una cartografía herida, donde los personajes que intervienen en la obra serán traspasados por el horror y la masacre que han implicado las Guerras Yugoslavas.

Palabras Clave: Angélica Liddell, herida, cicatriz, Guerras Yugoslavas.
\end{abstract}

ABSTRACT

In this study, we will analyse two semiotic nucleus upon which Angélica Liddell has based the internal structure of her work. Belgrado: wound and scar. With these two epidermic motives we confirm that liddellian's writing is pierced by a wounded architecture, where the caracters that take part in the work will be affected by the horror and massacre caused by Yugoslav Wars.

KEYWORDs: Angélica Liddell, wound, scar, Yugoslav Wars.

\section{INTRODUCCIÓN}

La obra, Belgrado: canta lengua el misterio del cuerpo glorioso, ganó el accésit al Premio Lope de Vega. Es una de las obras que la compañía Atra Bilis nunca ha representado por la estructura extensa de la obra. Solo se estrenó en enero de 2009 con la mano de Alfonso Ramos en la sala Valle-Inclán de la RESAD. La obra se estructura en 13 escenas, en las que los personajes están sometidos a la violencia, al silencio, a las no-respuestas de la catástrofe. No se define por la palabra. La palabra no es capaz de

* Recibido: 20-12-2018 / Aceptado: 09-09-2019. 
abarcar todo el horror, como señala Cavarero (2008); el horror cuyo efecto es paralizar, quedarse mudo y vulnerable ante la barbarie. La mirada que se desplaza porque no es capaz de mirar una imagen atroz que el individuo no puede ver, solo gira la cabeza o se tapa los ojos, es una manera de la que se siente vulnerable, herido. De ahí la importancia de una nueva escritura, que a través de ella el horror pueda leerse, no por quienes borran la mirada de las víctimas, sino por quienes quieren transformarlo y dar una corporeidad al silencio.

La guerra de Yugoslavia consistió en un conjunto de enfrentamientos étnicos y armados, entre la etnia serbia y los bosnios, eslovenos, croatas y albaneses. Los conflictos empezaron cuando Eslovenia y Croacia declararon su voluntad de independencia a la Federación Yugoslavia, tras su desintegración con la muerte de Tito en 1975. En 1991 se inicia el estallido del primer conflicto, después se expandiría a otros países, produciéndose guerras civiles, las cuales desencadenaron fatídicas consecuencias. La cadena de conflictos terminó en 2001 cuando la OTAN bombardeó la ciudad de Kosovo. Uno de los momentos más espeluznantes y violentos de la Guerra que recoge Angélica Liddell es la masacre de Srebrenica donde fueron asesinados más de 8000 de bosnios musulmanes. La masacre empezó el 11 de julio cuando el general Ratko Mladic dio la orden de entrar sin permiso en Bosnia. Después Milosevic, Izetbegovic y Tudman firman los tratados de Paz, cuyos acuerdos se prepararon en Dayton en noviembre de 1995. En 1996 los albaneses entraron en conflicto. Entre 1912-1941 los serbios ejecutaron limpiezas étnicas. Se produjo otra masacre donde 59 albaneses fallecieron. En 1999 intervino la OTAN, donde bombardearon la ciudad de Kosovo. En 2006 Milosevic muere en su celda tres semanas antes de que concluyera el proceso de su juicio. Ratko Mladic había sido condenado por el Tribunal Penal Internacional de la Haya en 2017. Según el informe preparado por el Centro de Investigación y Documentación en Sarajevo fija el número de 100.000 muertos, de los cuales 65\% eran musulmanes bosnios, un $25 \%$ serbios y un $8 \%$ croatas, mientras que el Centro Internacional de Justicia Transicional habla de 140.000 víctimas de la guerra.

Angélica Liddell, consciente del gran sufrimiento causado en la guerra de los Balcanes, se enfrenta al acto de escribir tras la ruina de la carne y la humanidad:

Lo que pasó en los Balcanes es el horror grabado a fuego y sangre, es lo más siniestro que ha pasado aquí, al lado nuestro, porque desde Italia se daba un salto y se llegaba. [...] Cuando esta gente destinada a aliviar el sufrimiento fracasa. Que fracase la literatura ya es un hecho, pero que fracase la acción es tan doloroso, tan frustrante. Quería hablar de toda esta gente que está pie de guerra, no de la que escribe, sino de la gente que trabaja en mitad del fuego (Hénriquez, 2007, p. 30).

Los protagonistas, Baltasar y Agnes, intentan recoger los momentos más escabrosos de la guerra. Son personajes que se encuentran al límite de sus cuerpos, 
de la violencia y la lucha, como comprobaremos en el análisis de la obra. Liddell va a intentar con la historia de esta guerra que la acción no sea un fracaso, sino lo contrario, una nueva esperanza de la que va a partir del fracaso de la palabra. Liddell se siente frustrada porque la revolución y la protesta no transforman al individuo. Es consciente del fracaso y de la mentira en el uso del lenguaje.

Se ha dado al lenguaje un lugar equivocado, una supremacía que no ha sido correspondida. Este fracaso va a permitir una lectura del otro. La posibilidad de reconciliación con el otro se debe a las estrategias que Angélica Liddell emplea y conforma una escritura corpórea, como tal redefine Acedo Alonso (2009) a la luz de las aportaciones de Margo Glantz y Luisa Valenzuela, es aquella escritura que

parte de una experiencia dolorosa, extrema, que se hace cuerpo textual para dejar testimonio, para hacer historia y memoria [...], que pone de manifiesto la dimensión discursiva de nuestra corporeidad, y desafía al poder -una red de discursos- que pretende des(es)cribirnos (Acedo Alonso, 2009).

A través de estos resquicios y grietas la literatura sobrevive, donde los supervivientes pueden escribir sobre el daño, donde las cicatrices rescatan lo olvidado. Belgrado se convierte en una ciudad cuya lengua se encuentra vulnerable y herida. La palabra en Belgrado es frágil y enferma. Se desliza entre los escombros y la sangre. Los himnos que encabezan en cada escena, según Silvia Monti, actúan como bisagrasintersección entre una escena y otra; conforman la lengua de la alteridad, la de la herida y la guerra que se sacraliza, y es venerada por los serbios. Estos textos breves poéticos son «espacios de suspensión, que permiten al lector/espectador distanciarse de lo que acaba de leer/escuchar y al mismo tiempo le dan al conjunto un ritmo pausado y casi hierático» (Monti, 2016, p. 163). García Manso (2014, p. 161) reflexiona sobre estos himnos que podrían ser utilizados para ser cantados y leídos durante la puesta de escena. El empleo de este lenguaje sagrado es otro modo de incidir en las estrategias empleadas para extirpar el dolor de la mente de las víctimas, silenciado por los discursos dominantes.

\section{LA HERIDA DEL INDIVIDUO}

Baltasar comete el error de socorrer al hombre a quien ha sido disparado en la calle, ante la impasibilidad de las personas. Este gesto provoca que Zeljko, (que aparece en la escena octava), un paramilitar, que pertenece a un grupo ultranacionalista serbio, lo secuestre. Este personaje actúa con violencia. Para Zeljko el castigo era su educación, la violencia con que le inculcaba era corpórea, se inscribía en su cuerpo. Su cuerpo obedece solo a esas órdenes que se han inscrito en él. El cuerpo es leído según la relación de poder (Foucault, 2000). Solo recibe el dolor a través del castigo: 


\section{Patricia Úbeda Sánchez}

acabé metido en grupos violentos

porque necesitaba que alguien me ordenara constantemente

porque yo no sé vivir sin recibir órdenes

porque necesitaba obedecer, obedecer (Liddell, 2007, p. 90).

El cuerpo de Zeiko es un cuerpo disciplinado, solo atiende a las órdenes que le enuncia. Está sujeto a la obediencia, a una relación de poder en el que se encuentra subordinado. En otro fragmento se observa cómo Baltasar se identifica con el asesino por las heridas, esto significa la igualdad entre uno y otro por la marca de la piel, la del dolor:

Tengo heridas como las tuyas, tengo heridas como las tuyas, ¿cómo puedo compartir heridas con las de un asesino? ¡Un pusilánime con la misma angustia con un asesino! (p. 106).

Sin embargo, Zeljko en un momento de vulnerabilidad, acaricia la colcha de terciopelo. Su rudeza se aplaca con la suavidad del terciopelo. Zeljko no se perdona a sí mismo cuando se da cuenta del momento en que ha sido arrastrado por la fragilidad. Las palabras performativas de Baltasar provocan el suicidio de Zejklo.

Acarició la colcha de terciopelo, Agnes.

Acarició lentamente la colcha de terciopelo.

Lo hizo con verdadera sensibilidad.

Se lo dije,

le dije, has acariciado la colcha de terciopelo, Zejlko,

entonces se pegó un tiro en la lengua,

se voló la lengua de un disparo.

Pero lo primero fue su lengua.

Su lengua saltó en pedazos por los aires (ibíd).

La lengua se destroza por el disparo. Se inutiliza cualquier posibilidad de comunicación. La imposición del silencio remite a la no-mirada, al lugar donde el horror se puede leer desde el silencio. La herida viene a ocupar toda la escena. Un grito que acaba siendo explosionado en mil pedazos, mudo. Zejhko se despoja de su cuerpo, de los rasgos humanos para convertirse en un alarido que se encarga de expresar la sonoridad de la violencia (Cavarero, 2009, p. 40). La herida se desplaza para ser escuchada, para ser leída desde el canto, desde la pérdida y sacralización de la lengua.

Entra en la casa de Borislav, hermano de Zljeko. Resulta llamativo el empleo del pañuelo en la escena última de la obra. Baltasar admira cómo dobla Borilav los pañuelos de algodón. Se lo dice y él le responde: «No me acostumbro a los de papel. A esos que usted hace pedazos» (2007, p. 134). Es llamativo porque según mi parecer trata de convertir la palabra en un pañuelo. El pliegue que le hace el pañuelo, «con 
auténtico esmero» es un gesto de vulnerabilidad. Es un pañuelo de algodón, lo dobla en un gesto minucioso. Borislav es consciente de la suavidad que tiene en sus manos. Es un hombre que está fuera del patrón de soldado de la guerra. Este pliegue podría ser una continuación a otra escritura, a una escritura del pañuelo. Gruia, en palabras de Walter Benjamin, afirma que el poema se inscribe desde la fragilidad y el vuelo: «Es decir se trataba de convertir el poema en pañuelo» (2016, p. 121). Pero también añade el desgarro de sus roturas. De esta forma, nos encontramos con otro discurso construido por los trozos de papel que ha roto Baltasar. Su gesto es más áspero que el anterior. Los dos tejidos representan dos fuerzas opuestas entre sí, la brutalidad y la suavidad, dos formas distintas de inscribir la historia en la memoria de quienes han sobrevivido. Por lo que la escritura liddelliana no solo es una escritura dramática, sino también una escritura corpórea, que deja huella en la historia personal del individuo, ya sea describiéndola o remendándola de los despojos y costuras desplazados al silencio.

\section{LA HERIDA DEL LENGUAJE}

¿Cómo escribir el dolor de la humanidad tras la catástrofe? ¿Cómo escribir el dolor de una ciudad destruida desde la raíz, desde el grito? Ese dolor que Celan plasmó en la lengua alemana, la lengua de los alemanes que asesinaron a sus padres, se expresó a través de la poesía. Según Blanchot (2002) la temática del texto sobre lo que sucedió en Auschwitz se convierte en testimoniar sobre la imposibilidad de escribir sobre él. Cuando llega el momento en que el dolor supera a los discursos poéticos y ficcionales, la lengua se atrofia, se deforma (Vasserot, 2014, p. 10). Es necesario a recurrir a otro lenguaje para que esta resista.

Los supervivientes de la guerra y de los holocaustos intentaron reconstruir una identidad marcada por la culpa y la vergüenza, una identidad que no era correspondida. El escritor Primo Levi, tras haber pasado por el Holocausto, no se dio cuenta hasta entonces de su identidad, una identidad que fue inscrita bajo el estigma del horror y la ceniza. Al volver a su tierra temía no poder ser escuchado, que su familia no atendiera el grito que guardaba en su interior. Por lo que escribió la primera parte de sus memorias, centrándola en los momentos vividos en el campo de concentración de Auschwitz no con un lenguaje excesivo y sangriento, sino con un lenguaje más propio de un científico ${ }^{1}$.

El lenguaje es cuestionado en casi toda la obra. En la escena duodécima llama la atención la decepción de un personaje, médico, con que justifica la inutilidad de la

\footnotetext{
${ }_{1}$ «Levi acostumbrado a mirar la realidad con los ojos analíticos de un científico, un tipo de científico especial puesto que trabaja la química inorgánica, contempla las cenizas y el lenguaje desde la misma perspectiva» (Glantz, 2008, p. 163).
} 
lengua. La palabra no sirve para nombrar o describir el horror producido. El ruido aísla al individuo y no existe espacio para la comunicación:

Prefiero pasar diez horas en esta fábrica

que curar un rasguño.

Me mareo de pensarlo.

El ruido de las máquinas.

Me aísla de los hombres.

Tampoco se puede hablar.

Es mejor no hablar.

Inutilizar la lengua.

Con ese ruido desaparece la lengua

la lengua aquí no sirve (Liddell, 2007, p. 131).

El lenguaje en la capital de Belgrado se destroza, donde ha sido cicatrizada la palabra, el lenguaje no tiene la capacidad de sostenerse, de no evitar salir afectado por la crueldad y la violencia²:

El lenguaje se pierde.

Se pierde en estos lugares.

Kosovo,

allí no se forjaba la historia

allí no se puede combatir la injusticia,

allí no se podía amar la humanidad,

solo miseria y salvajismo (Liddell, 2007, p. 16).

Agnes se siente decepcionada y desconfiada con la palabra. Su trabajo consiste en informar y comunicar los hechos que están ocurriendo en la guerra. Sin embargo, no se siente capacitada de seguir relatando a través del lenguaje de la guerra porque lo considera falso y arbitrario. La única vía de expresar la guerra sin poder quebrarse o sentirse vulnerable es la literalidad. Ha de sostener el lenguaje bajo los moldes y arquetipos de la información periodística porque si no la escritura se deforma. Aun así, Anges expresa que no puede continuar escribiendo a través de un lenguaje que le ha privado de libertad. Desea mostrar la realidad de una ciudad sitiada por el poder del fuego.

No se puede hablar del horror si no es canalizado a través de un lenguaje denotativo: «Y el torturador no encuentra otro nombre / que sea el torturado» (2007, p. 24). El dolor solo puede ser nombrado por medio de la noticia y la precariedad simbólica. Sin embargo, Angélica Liddell cuestiona la imagen dada en los medios de comunicación, una imagen que oculta a los oprimidos, que no conmociona y se adecua a la opinión general (2010, p. 41). Es desde esa contradicción que quiere revelar

\footnotetext{
${ }^{2}$ Es inevitable pensar en la reflexión de Scarry (1965) sobre la desconstrucción del lenguaje como consecuencia de la tortura ejercida sobre el prisionero. El dolor reduce el lenguaje hasta el punto de que el prisionero solo emite alaridos y balbuceos.
} 
las miserias que ocultan los políticos sobre la historia de las víctimas. El discurso de los dictadores ofrecido por los medios de comunicación desdibuja la identidad de los supervivientes y de las víctimas.

Liddell quiere romper así el pacto ficcional del lector, golpear su cabeza sobre una mesa de disección, proponiendo un texto sin adornos estilísticos, ni un léxico edulcorado, donde solo el lenguaje de la no-literalidad pueda transmitir las atrocidades de la guerra de los Balcanes. Un texto informativo que solo tiene la función de transmitir los hechos que se han producido desde el fuego y el llanto. Sin embargo, no puede eludirse la construcción de la metáfora en él, ya que esta será un apoyo cuando el lenguaje se quiebra por el dolor. El dolor solo es perceptible cuando es contemplado. Derrida (2002) propuso que el texto debe precisar de un género para que pueda ser leído. El reconocimiento de ciertos objetos que puedan ser visualizados en el imaginario común sobre el horror, propician que lo que estamos leyendo nos espante. Como lectores nos sentimos vulnerables, nos hemos desprovisto de metáforas por las que podíamos evadirnos de la barbarie. Anxo Abuín (2015) alude a este lenguaje informativo a una poética de las listas, aquella en la que

las listas se asientan, naturalmente, en la idea posmoderna de no-relato (...). El uso de una escritura, manifiesta la resistencia ante los discursos totalizadores y autoritarios, y la disolución del acontecer dramático, porque la realidad es diversa y caótica y el lenguaje insuficiente para dar cuenta de su diversidad impenetrable (Abuín, 2015, pp. 49-50).

Proponemos en este trabajo otra poética, una poética del cuerpo, donde las incursiones físicas se resisten al poder y al sometimiento atroz sobre los individuos, donde es posible leer y construir a partir de esta poética discursos subversivos donde tanto la angustia colectiva como la individual pueden ser escuchadas.

\section{UNA CARTOGRAFÍA QUEBRADA}

La mayoría de los bosnios se quedaron sin víveres de agua, enfrentándose al frío y al hambre, quedaron a merced de los serbios y de las tropas holandesas que les brindaron un cobijo que después sería una trampa, llevándoles por un camino fortuito a la muerte. Bosnia era declarada por la ONU «zona segura». Las tropas serbias entraron, como hemos anunciado en la introducción el 11 de julio de 1995. La mayoría de los bosnios fueron alojados a una fábrica de baterías, Potocari, donde también encontraron una muerte segura. El resto tomó el camino del éxodo.

En este país todos son supervivientes. Han sobrevivido a los tiranos

Kosovo a veinte grados bajo cero y lo ético.

Es el Danubio,

es el Danubio el que está colaborando en toda esta locura.

Atestado de cadáveres (Liddell, 2007, p. 15). 
Las ciudades Belgrado y Srebrenica se convierten en montañas de cuerpos sin identidad hasta que organizaciones a favor de las víctimas y sus familiares lucharon por recuperar su dignidad y así cerrar la herida. Muchas de las familias se han encontrado con los cuerpos de sus familiares sin la totalidad de los huesos. La mayoría fueron despedazados, mutilados y enterrados en fosas secundarias. En una de ellas, Kamenica, todavía se encuentran miles de cuerpos sin exhumar. Las familias tienen la esperanza de hallar la mayoría de los huesos para poder darles una sepultura digna y acabar así con el infierno. Belgrado es una ciudad que se ha construido por la mancha, por la búsqueda incesante de recuperar sus recuerdos, su historia personal y colectiva. Liddell muestra una ciudad levantada con los restos de los cadáveres, cuya lengua sobrevive débil, la dramaturga va a intentar construir una nueva lengua sobre las cenizas, con la que puede identificarse el individuo tras la masacre:

Dragan: Belgrado es una de las ciudades más antiguas de Europa, con más de 7.000 años de historia, conquistada por 40 ejércitos y 38 veces reconstruida desde su ruina.

¿Qué le parece extraño?

¿Quiere ver la mesa dónde estudió el Mariscal?

En 1945 el mariscal unificó las seis repúblicas manteniendo la paz durante 30 años (p. 8).

Es significativo que este fragmento abra la acción en el Museo de la Revolución, donde es un espacio de la memoria. Belgrado pasó ser conquistada por los celtas y los otomanos en 1455. Los turcos se retiraron en 1881. Serbia reclamó el territorio, poblado por la mayor parte por los albaneses. La ruina es la característica de la conquista. Belgrado es una ciudad cicatrizada, cosida con la ira y la sangre de la guerra. Ioana Gruia destaca su potencial corrosivo: las ruinas funcionan, «a la vez como una piel agresiva (que se renueva siempre construyendo un cerco asfixiante» (Gruia, 2016, p. 118). Asimismo, la ruina significa una abertura al pasado y al presente. Los escombros son la huella, la cicatriz que han dejado detrás de sí la guerra, el fuego y la historia. La ruina, cuya sombra es inquietante, trastoca lo cotidiano y lo íntimo, llegando incluso a amenazar la lengua con que está construida la identidad del individuo. Es la conexión de la historia colectiva a la individual, ya que como analizaremos, los restos están presentes en el pensamiento del individuo, sobre todo en las voces de los protagonistas, cuyas historias son atravesadas por los escombros:

Baltasar: Es extraño.

Que esta ciudad pueda seguir llamándose Belgrado, que uno pueda seguir viajando a Belgrado, es decir me marcho a Belgrado, o voy a coger un avión destino a Belgrado, es extraño que Belgrado exista, decir Belgrado, la palabra Belgrado y que Belgrado sea una ciudad, en la misma ciudad de los asesinos. No quiero ver la mesa dónde estudió. No quiero perder la fe en la Educación (Liddell, 2007, p. 9).

Belgrado es el espacio del odio por el otro, de la sed de venganza y poder. El nombre de la ciudad se convierte en un nombre extraño. El protagonista es consciente 
la maldad de las personas, sin embargo, quiere creer y mantenerse firmemente en la ignorancia. El nombre de la ciudad es un nombre usado bajo la mentira y la violencia. La propaganda política ha dado una imagen de victoria y armonía, mientras al otro lado de la ciudad, en las fronteras seguían las luchas encarnecidas entre etnias.

La herida aparece en los espacios aniquilados, donde los rostros se hallan desfigurados, cubiertos por miles de capas de silencio. Nancy ya se refería a los campos de exterminio como espacios no representantes de la representación, donde los sujetos carecen de rostro y de cuerpo para poder existir, para poder considerase autónomos e independientes del poder. Los campos construidos por muros, por cemento y ceniza se imponen, dominan sobre los cuerpos heridos, deformados, aquellos que no imitan «la representación» que quiso para sí el nazismo: un bloque de sentido, sin fisuras, «cuya afirmación y triunfo tienen lugar en el silencio» (Nancy, 2006, p. 52). Como bien señala Acedo para poder reafirmarse sin fisuras necesita de un sujeto sin rostro, sin rasgos humanos (Acedo, 2013, p. 6) ${ }^{3}$. Según Cavarero la no-representación se da en la mirada cuando se aparta por cómo es dada la repugnancia o la ofensa. Aunque Belgrado no se componga de la arquitectura concentracionaria, encarna vivencias inmirables. Liddell recurre a la repetición, al cántico para poder ser reveladas y comprendidas las fisuras de una ciudad soterrada bajo la imagen del no-rostro:

Al contrario de los edificios públicos, las habitaciones son espacios que, a pesar de brindar protección e intimidad, se tambalean bajo la sombra de la violencia y del mal. La geografía urbana se agrieta llegando a desestabilizar la tranquilidad de los personajes. Se ven amenazados por las roturas externas que se cuelan en sus mentes. No se pueden desplazar y se revelan en una explosión violenta, negando la posibilidad de fuga.

\section{LA HERIDA DE GÉNERO}

La herida no solo traspasa los cuerpos de las ciudades y del individuo, sino también los cuerpos de las mujeres. En la guerra de Yugoslavia, como en el Holocausto, las mujeres fueron violadas de manera sistemática ${ }^{4}$. Agnes, el alter-ego de Angélica Liddell, confiesa sus heridas, sus cortes en las que subyacen una narración violenta y traumática:

Agnes: Ya me empiezo a cortar con cosas.

\footnotetext{
${ }^{3}$ Primo Levi comentó la no figuración del rostro del enemigo. Para él y otros supervivientes el enemigo era quien no tenía rostro humano tampoco nombre: «estaban alejados, eran invisibles, inaccesibles» (2013, p. 193).

${ }^{4}$ Es necesario incidir en la cuestión de que el número de testigos era menor en el caso de las mujeres. Según Glantz (2008, p. 216) se debe a dos motivos, uno biológico y otro etimológico.
} 


\section{Patricia Úbeda Sánchez}

Son los accidentes que llegan,

que llegan el accidente,

un corte superficial, por azar, un dedo,

sin inocencia,

son ya un corte y una quemadura,

¿nunca te ha pasado?

Cuando piensas en otra cosa

y te cortas un dedo (Liddell, 2007, p. 24).

El fragmento con que inicia el primer monólogo muestra la carga semiótica de la herida. La intención de autolesionarse no es inocente, sino justificada. La herida confiere así en términos deleuzeanos como el acontecimiento, el accidente esperado a que se encarne en la piel. El cuerpo va a ser el soporte, por donde se inscribe la herida como acontecimiento. El corte refleja a otros pliegues que desvelan las voces de aquellas personas que han sido caídas en el olvido. La vulnerabilidad que Liddell enseña al principio culmina en la escena décima cuando Agnes se sacrifica. Baltasar lo cuenta tras regresar a su tierra. Sabemos que, a través del relato de Baltasar, se entrega a su agresor y asesino:

Baltasar: Te lo voy a contar otra vez.

Por si todavía no lo has comprendido.

Ella sabía que la iban a matar,

me lo dijo,

con sus propias manos.

Agnes me dijo, si me acuesto con este tipo me matará.

Y la mató, como ella dijo.

Con sus propias manos.

La estranguló (p. 124).

Angélica Liddell denomina este acto de entrega a su agresor como un sacrificio poético. Agnes en latín significa cordero, es el cordero que se sacrifica. Según Bataille (1993) la carne es la revelación de la pasión, de la intimidad, la suspensión de la ética. La carne herida revela su intimidad y la intimidad de las mujeres que fueron violadas y asesinadas.

La herida está manchada por la humillación y la pérdida genealógica. El genocidio y la guerra son dos sistemas o mecanismos paralelos de violencia que someten a las mujeres al silencio y a la humillación. Los cuerpos de las mujeres fueron objetos de violación sistemática por los militares como táctica de guerra. Los espacios sagrados como el vientre de la madre son extirpados o violados. La violencia irrumpe con más efectividad en aquellos cuerpos que no se pueden manchar: «Se practicará sistemáticamente la desfiguración, la profanación de los espacios considerados, el de la muerte física o la violencia de las mujeres» (Heritier, 1996). El propósito de estas prácticas innombrables «no es la muerte de la víctima, sino deshacer su propio 
nacimiento» (Osorio, 2005, p. 83). Es la desaparición de su identidad, de su huella genealógica, en sustitución por otra, estigmatizada por la vergüenza y la culpa.

Desde una perspectiva estructural el cuerpo (textual) se sacrifica para dar continuidad a la palabra. El sacrificio muestra la angustia de una parte de Occidente, la de una ciudad que se ha quedado con una gran parte de la sociedad huérfana de recuerdos. Solo la palabra ofrece a través del sacrificio poético la devolución de una nueva identidad y la esperanza de los pueblos masacrados por los mecanismos de la violencia y el poder.

\section{Conclusiones}

El propósito de esteartículo es analizar desde una poética corpórea fundamentada en dos motivos epidérmicos, la herida y la cicatriz, que configuran la pieza dramática Belgrado, lengua canta el misterio del cuerpo glorioso, de Angélica Liddell. El cuerpo va a ser clave como inscripción de la memoria fracturada de una ciudad. Los personajes son atravesados por la violencia y el horror de la guerra. Sus cuerpos aparecen marcados por heridas y cicatrices, no solo por la violencia bélica sino también por la violencia personal que se produce en el ámbito cotidiano e íntimo. Belgrado se convierte en un himno que sacraliza y rinde homenaje a aquellos que fueron masacrados por el mandato del dictador Slodoban Milosevic y la pasividad de los estados europeos. Angélica Liddell con esta pieza intenta no solo rescatar las voces que han sido silenciadas por el genocidio, devolver la voz a esos cuerpos desmembrados, sino también rehacer la historia que ha desubjetivizado la identidad no solo de un país cosido por las ruinas y miserias del ser humano, sino de las mujeres que han sido violadas de forma sistemática. Belgrado se presenta como geografía inscrita en la esperanza y en el duelo. La literatura no es sino el reflejo, no del fracaso como defiende la dramaturga en un principio, sino del intento de que la comunicación funcione, de que la palabra que se inscriba nombre sin deformarse el genocidio de varias naciones.

\section{BibliografíA}

Acedo Alonso, N. «La escritura corpórea en la narrativa de Luisa Valenzuela. LIII Congreso Internacional de Americanistas», en Disciplinas, discursos y prácticas corporales: una mirada a la construcción cultural de los cuerpos y las identidades, Universidad Iberoamericana de México, México, 2009.

, «Desplazamientos. Una reflexión sobre la posibilidad de escuchar el horror»; en Kamchatka: revista de análisis cultural, 2 (2013), pp. 85-104. 
Patricia Úbeda Sánchez

Aвuín, A., «Listas y números en el teatro español actual», Ínsula, 823-824 (2015), pp. 49-50.

Bataille, G., La teoría de la religión, Madrid, Taurus, 1993.

Blanchot, M., La folie de jour, París, Éditions Gallimard, 2002.

Cavarero, A., Horrorismo. Nombrando a la violencia contemporánea. Barcelona, Trotta, 2009.

Deleuze, G., Lógica del sentido, Barcelona, Paidós, 2011.

DerridA, J., Schibboleth. Para Paul Celan, Madrid, Arena Libros, 2002.

Foucault, M., Vigilar y castigar, Madrid, Siglo XXI, 2000.

García MANSO, M. L., «Las guerras de la ex-Yugoslavia en la creación dramática femenina española», Revista de Escritoras Ibéricas, 2 (2009), pp. 145-169.

Glantz, M., La polca de los osos, Chile, Cuarto propio, 2008.

GRUIA, I., La cicatriz en la literatura contemporánea europea, Sevilla, Renacimiento, 2016.

Henríquez, J., «Entramos a vivir y morir en el escenario», Primer acto, 321 (2007), pp. 21-30.

HÉRITIER, F., «Réflexions pour nourrir la réflexion», Seminaire de François Héritier. De la violence. Éditions Odile Jacob, París, 1996.

LeVI, P., Si esto es un hombre, Madrid, Austral, 2013.

LidDell, A., Belgrado, canta lengua el misterio del cuerpo glorioso, Bilbao, Artezblai, 2007. , «El mono que aprieta los testículos de Pasolini», en El sacrificio como acto poético, Madrid, Continta me tienes, 2010.

MonTI, S., «La escritura dramática de Angélica Liddell: Belgrado canta lengua el misterio de un cuerpo glorioso», Cuadernos Aispi: Estudios de lenguas y literaturas hispánicas, 7 (2016), pp. 155-172.

, Verdad y mentira en el sentido Extramoral, Madrid, Gredos, 2011.

Osorio, A., «Violencias extremas y etnicidad: la ex Yugoslavia», Alteridades, 15, 30 (2005), pp. 75-84.

SCARry, E., Body in pain. The making and the unmaking of the world, Oxford, UniversityPress, 1965.

VAsserot, C., «Prólogo: La pasión según Angélica Liddell: de la palabra poética al sacrificio dramático», en El sacrificio como acto poético, Madrid, Continta me tienes, 2014. 